\title{
Shifting avian spatial regimes in a changing climate
}

\author{
Caleb P. Roberts $\circledast^{1,2 \star}$, Craig R. Allen², David G. Angeler ${ }^{3,4}$ and Dirac Twidwell'
}

In the present era of rapid global change, development of early warnings of ecological regime shifts is a major focus in ecology. Identifying and tracking shifts in spatial regimes is a new approach with potential to enhance understanding of ecological responses to global change. Here, we show strong directional non-stationarity of spatial regimes identified by avian community body mass data. We do this by tracking 46 years of avian spatial regime movement in the North American Great Plains. The northernmost spatial regime boundary moved $>590 \mathrm{~km}$ northward, and the southernmost boundary moved $>260 \mathrm{~km}$ northward. Tracking spatial regimes affords decadal planning horizons and moves beyond the predominately temporal early warnings of the past by providing spatiotemporally explicit detection of regime shifts in systems without fixed boundaries.

\begin{abstract}
cological systems are complex and hierarchically organized in - space and time ${ }^{1}$, yet efforts to quantify ecological resilience and predict regime shifts have focused on the temporal dimen$\operatorname{sion}^{2,3}$. This approach works well when the spatial boundaries of ecosystems are clear and fixed. For example, theoretical inference of early warning and pending regime change has advanced through studies of shallow lake ecosystems, which have hard boundaries that make it possible for scientists to ignore external spatial dimensions of these complex systems before regime shifts ${ }^{4,5}$. Advancements have been made by extending early warning indicators such as autocorrelation into spatial contexts ${ }^{6-8}$. However, the theory and methods still assume fixed spatial boundaries of regimes despite their being situated in open, complex and dynamic systems?
\end{abstract}

The concept of spatial regimes represents a new frontier in resilience science that unifies both spatial and temporal dimensions into the study of regime persistence and change across ecosystems without fixed boundaries ${ }^{10,11}$. Spatial regimes are defined as spatial extents with discrete boundaries at a given scale that exhibit relative homogeneity in structure and composition maintained by feedback mechanisms ${ }^{10,12}$. Theory recognizes that all ecological regimes have geographic limits (spatial boundaries) but those limits may not be fixed or known ${ }^{12}$. This perspective differs from classical investigations of resilience and regime shifts, which have focused primarily on systems with well-known boundary limits and where critical transitions have been observed over time ${ }^{2,13}$. Many systems have porous boundaries (for example, grasslands and oceans), many taxa are highly mobile (for example, birds and pelagic fish), and system boundaries can shift rhythmically or in response to change drivers (for example, climatic and anthropogenic boundaries) ${ }^{14}$. There is no single appropriate scale to define spatial regimes in space or show how spatial regime boundaries move over time; this body of theory has only recently developed as more powerful metrics have emerged ${ }^{9,12}$.

Here, we build on decades of ecological research on body mass size distributions ${ }^{15-17}$ to disentangle alternative scientific predictions about the behaviour of large-scale spatial regimes in an era of global environmental change. One prediction, on the basis of an extension of resilience theory, is that external environmental forcing will cause idiosyncratic behaviour in spatial regimes undergoing collapse, similar to the responses of individual species before extinction ${ }^{18,19}$. An alternative hypothesis is that spatial regimes are non-stationary and will be conserved because of strong positive feedbacks, such that spatial regime boundaries will move in a directional, orderly trajectory $y^{10,11}$. Disentangling the predictable and orderly from the unpredictable and idiosyncratic provides the foundation for early warnings of critical transitions in nature ${ }^{9}$.

\section{Results and discussion}

We analysed 46 years of avian community body mass distribution data from the Great Plains of North America to identify spatial regime boundaries and then identified patterns in latitudinal spatial regime boundary movement over time. Analyses revealed regional, poleward shifts in both the southernmost and northernmost spatial regime boundaries. This supports our alternative hypothesis of conserved, directional and relatively ordered movement (Fig. 1). The northernmost regime boundary has moved faster: $>590 \mathrm{~km}$ from 1970 baselines $\left(0.121 \pm 0.080^{\circ}\right.$ latitude per year $\left(13 \mathrm{~km} \mathrm{year}^{-1}\right)$ at $90 \%$ confidence interval, CI) compared to about $260 \mathrm{~km}$ for the southernmost boundary $\left(0.053 \pm 0.051^{\circ}\right.$ latitude per year $\left(6 \mathrm{kmyear}^{-1}\right)$ at $\left.90 \% \mathrm{CI}\right)$. These differential rates of spatial regime movement (northern versus southern boundaries; Fig. 1) match expectations associated with Arctic amplification and accelerated change in northern versus southern latitudes of temperate North America $^{20}$. Consistent with existing theoretical foundations ${ }^{21}$, the regime moving more quickly also carries with it greater interannual volatility in its location (Fig. 1).

Directional (northward) change in spatial regime boundaries occurred with relative stability in the number of spatial regimes identified over the past half-century $(2.91 \pm 0.39,90 \%$ CI; Fig. 2). The number of spatial regimes detected ranged from 0 to 5 , with transitory regimes occurring periodically. Changing from the average of three spatial regimes, a fourth spatial regime emerged more consistently in the 2010s decade (2010-2015; Fig. 2). In the early decades of our study, spatial regime boundaries showed some congruence with the Great Plains biome's historic extent (Fig. 2). But in subsequent decades, spatial regimes expanded (southernmost

'Department of Agronomy \& Horticulture, University of Nebraska, Lincoln, NE, USA. ${ }^{2}$ Nebraska Cooperative Fish and Wildlife Research Unit, School of Natural Resources, University of Nebraska, Lincoln, NE, USA. ${ }^{3}$ Department of Aquatic Sciences and Assessment, Swedish University of Agricultural Sciences, Uppsala, Sweden. ${ }^{4}$ School of Natural Resources, University of Nebraska, Lincoln, NE, USA. *e-mail: croberts6@unl.edu 

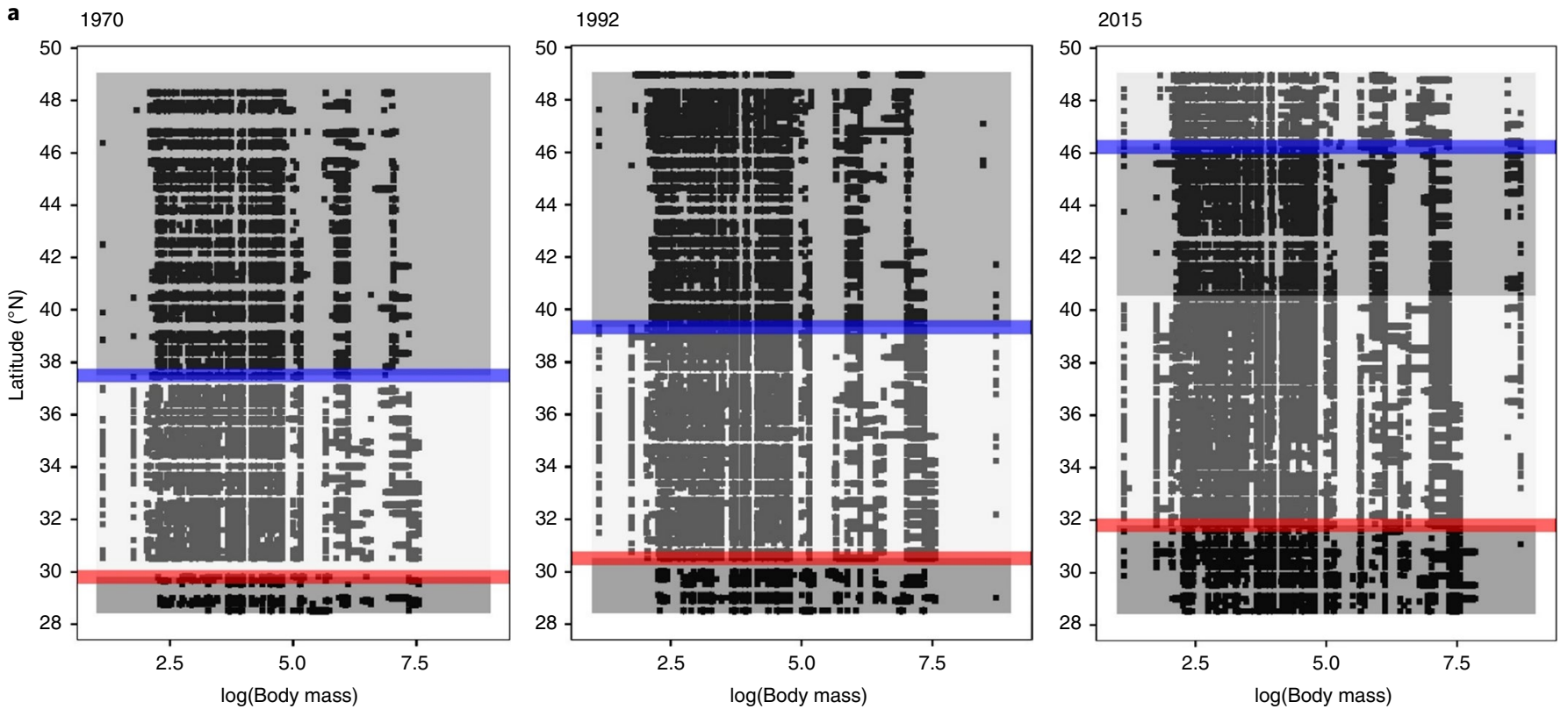

b

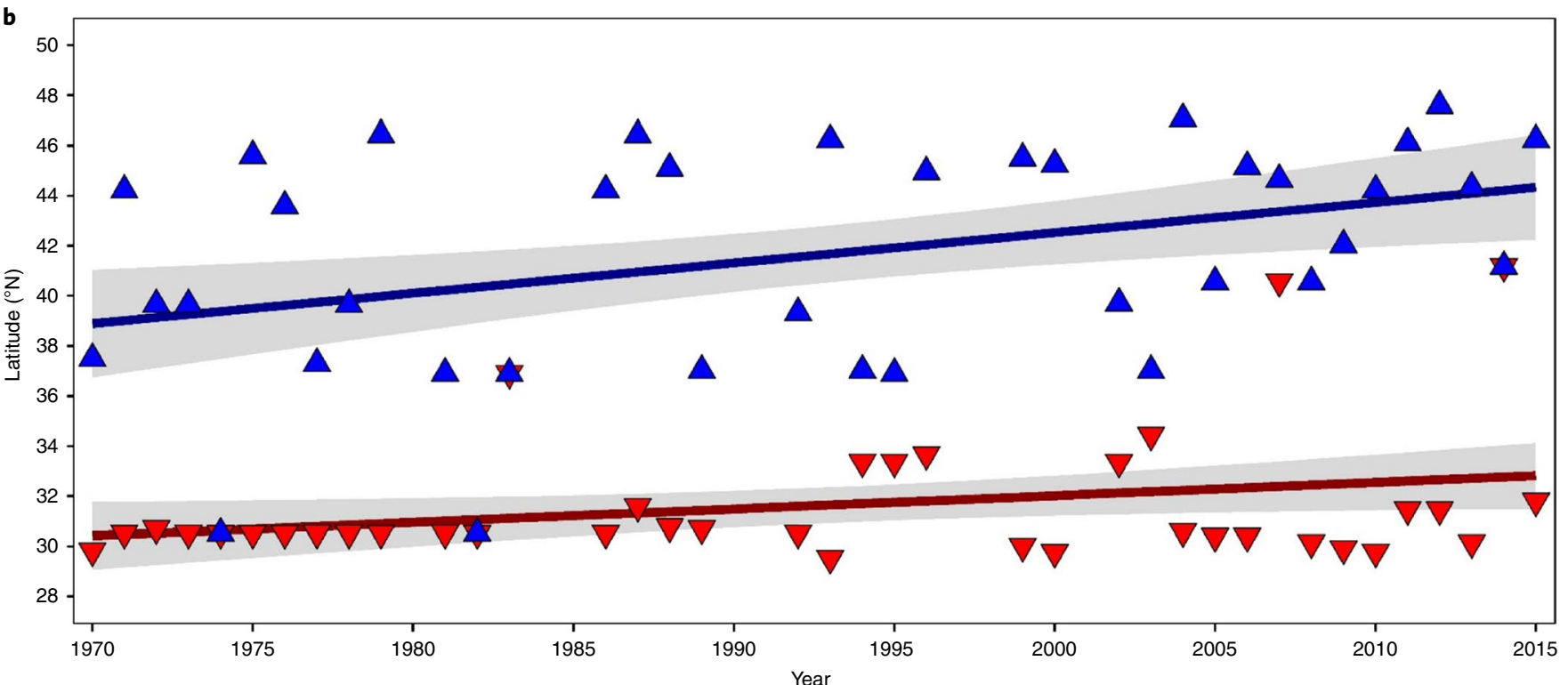

Fig. 1 | Shifts in spatial regime boundaries demonstrated by breeding bird body mass discontinuities from 1970 to 2015 in the North American Great Plains. a, Latitudinal spatial regime boundaries ( $y$ axis) determined by log-ranked avian body mass discontinuities ( $x$ axis). Black dots represent body mass aggregations identified using discontinuity analysis in each breeding bird survey route in the transect. Grey-scale boxes represent spatial regimes. The northernmost and southernmost spatial regime boundaries are highlighted by blue and red lines, respectively. b, Spatial regime boundaries (blue triangles, northernmost; red triangles, southernmost) detected each year. Lines represent modelled northernmost and southernmost spatial regime boundary movement over time with $90 \% \mathrm{Cl}$ (grey ribbon). When northernmost and southernmost boundaries were the same (that is, when only one spatial regime boundary was detected in a year), blue and red triangles overlap.

regime), moved northward (middle regime) and contracted (northern regimes), providing evidence that spatial regimes are rapidly reorganizing and diverging from historic biome extents by the 2010s (Fig. 2)

The cause of the northern movement is unknown but it is congruent with biogeographical patterns of change for multiple global change drivers in central North America. Climate change, anthropogenic pressures, wildfire trends and woody plant invasions have all operated along a putatively south-to-north trajectory over the past decades, particularly in the Great Plains ${ }^{22-27}$ (Fig. 3). Irrespective of mechanism, this finding suggests that spatial regimes, and the animal body mass distributions we use to identify regimes, are conservative, as our alternative hypothesis predicts.

The addition of a spatial dimension without fixed boundaries to resilience quantification and regime shift detection allows for increased planning horizons in the face of global environmental change. We use the movement of spatial regime boundaries in the interior of central North America as an illustration (Fig. 4). For a network of protected lands in this region, advanced detection would come from tracking spatial regime boundaries in a surrounding window (Fig. 4). Knowing the 'baseline' boundary in 1970 and its average northward movement pattern, protected lands in the Flint 

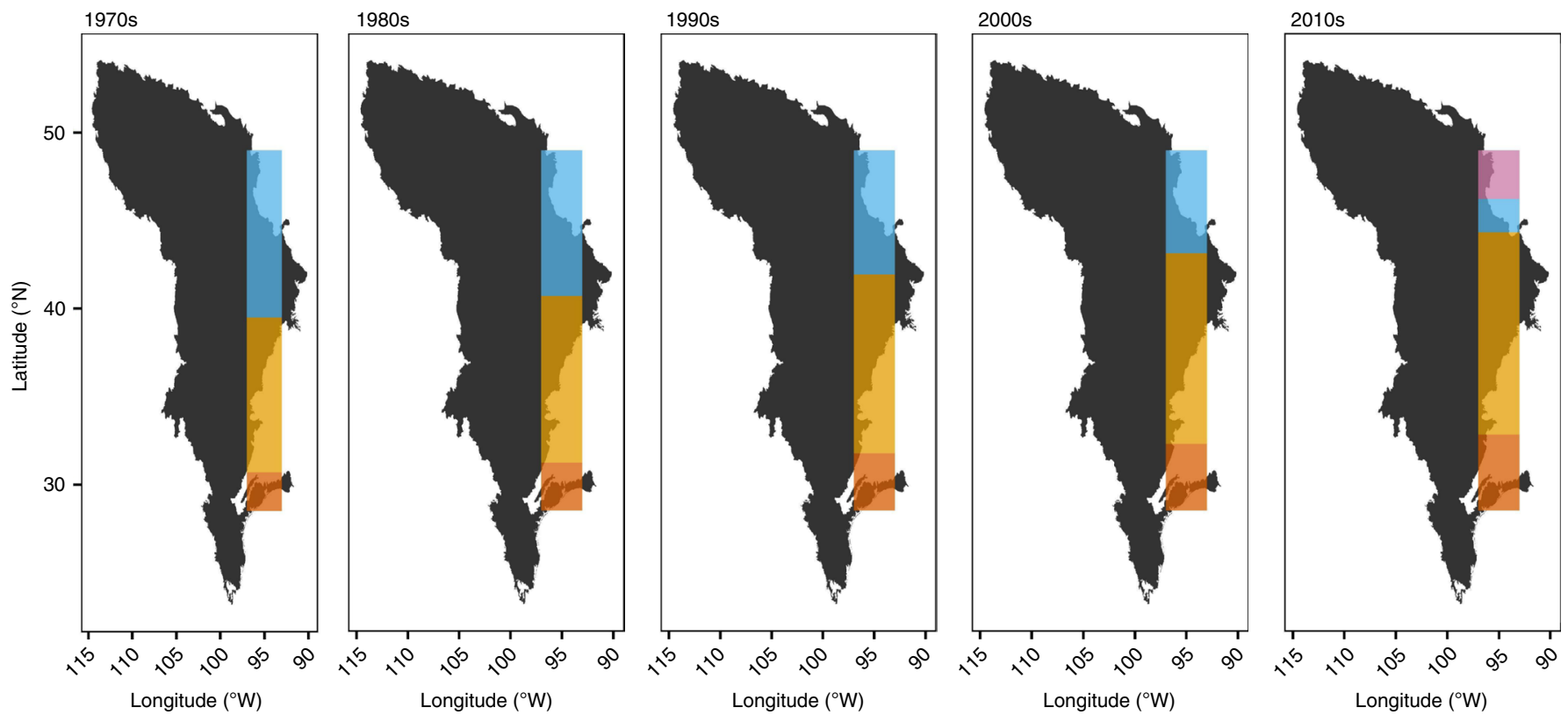

Fig. 2 | Visualization and tracking of predicted decadal spatial regimes and their boundaries in the North American Great Plains. Black polygons represent the historic Great Plains biome extent. Coloured bars represent the predicted extents of spatial regimes in the study area over five decades. The number of colours represent the average number of spatial regimes detected in each decade.

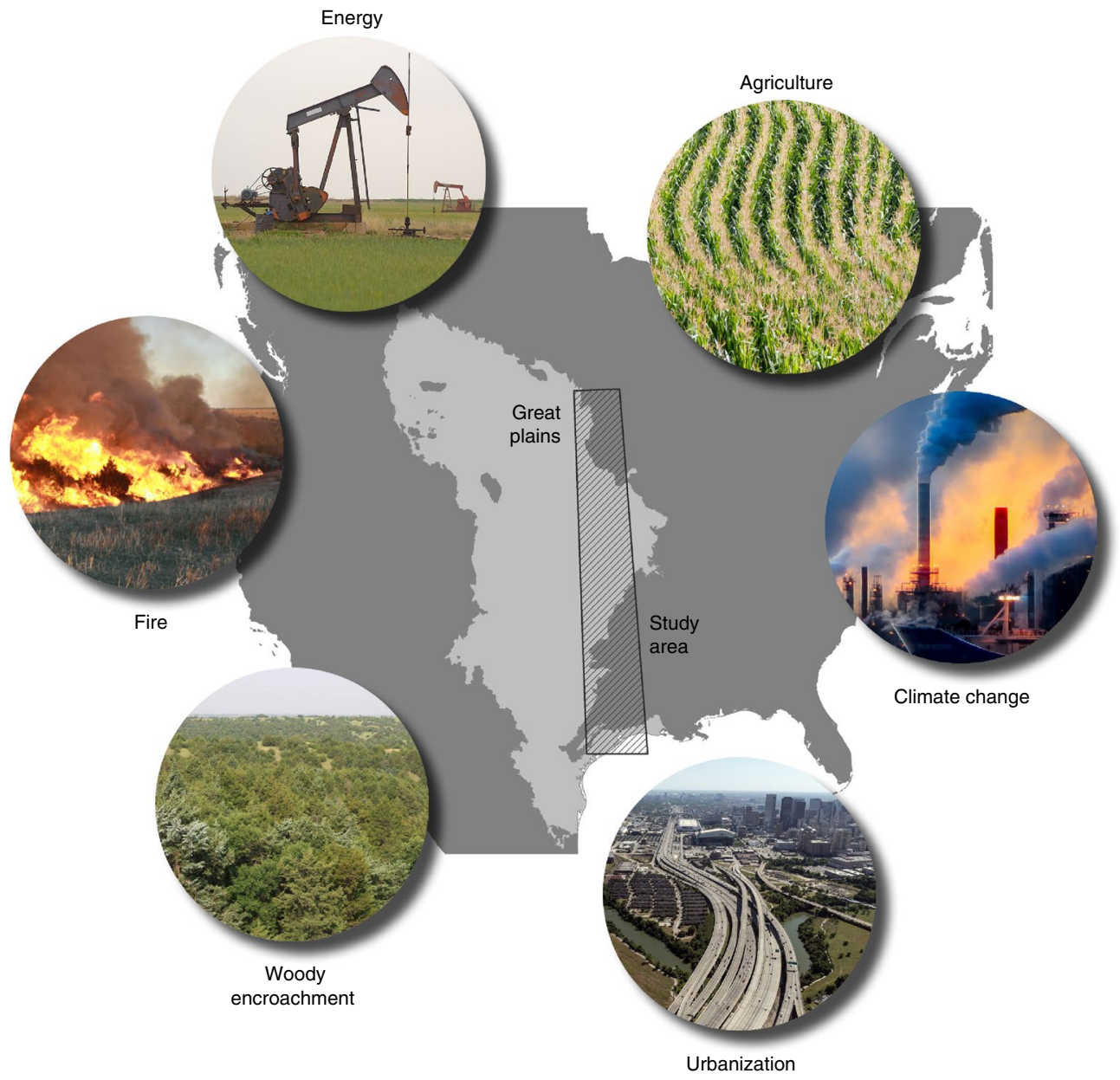

Fig. 3 | Global changes influencing ecological regimes in central North America. Global changes, such as agricultural land conversion, anthropogenic climate change, urbanization, woody plant encroachment, increasing frequency/intensities of fire and energy development, are all driving ecological change in the North American Great Plains in a putatively south-north trajectory. Predictable, directional (poleward) movement of spatial regime boundaries in the Great Plains corresponds to the trajectories of global change drivers. Credit: USDA, NRCS Texas (agriculture). 
Hills ecoregion had decades of early warning that the entire ecoregion would soon experience an imminent transition; protected lands in the Western Corn Belt Plains ecoregion had $>40$ year of advanced warning (Fig. 4). In this example, a spatial regime boundary moving closer to a given location warns of an impending abrupt change-but a change that is relatively predictable as one regime replaces another. Theoretically, this should precede traditional generic signals of early warning of a regime shift ${ }^{28-30}$. Traditional early warning signals, such as critical slowing down, rising variance and flickering, rely on ecological data departing and returning to a baseline; this essentially requires a temporal lag before detecting even a single iteration of a signal ${ }^{6,29-31}$.

Our analysis suggests that it is now possible for the science of early warning to foster earlier adaptation in environmental management at subcontinental scales, forcing increased awareness of the challenges inherent in the management of stationary ecological conditions at a given location ${ }^{32}$. As a moving ecological regime approaches or passes a given location, it becomes increasingly likely that the existing ecological regime will collapse and a location managed to reflect earlier regimes will become a 'ghost of regimes past'. Policies that mandate management for ghosts of regimes past, regardless of the surrounding regime, may be setting themselves up for failure in an era of global change and uncertainty ${ }^{33,34}$. Acknowledging this reality has been difficult for ecosystem managers at a given location to accept. Laws such as the Endangered Species Act in the United States currently lack the flexibility necessary to solve this general problem of managing for ghosts of past regimes because single species are often the prime conservation targets. To illustrate this: in our example of spatial regime boundaries shifting northward past a conservation land in central North America (Fig. 4), land managers tasked with preserving historical plant-animal associations will continue to burn and mechanically remove woody plants to maintain remnants of the historic tallgrass prairie regime while simultaneously losing ground to encroaching woody regimes due to positive feedbacks (for example, propagule pressure and avian seed dispersal ${ }^{27,34}$. Once these coercive management efforts wane, positive feedbacks will quickly shift to the basin of attraction of the surrounding spatial regime ${ }^{12,35}$. An alternative approach for land managers is to embrace northward-moving spatial regimes and align conservation efforts in northern protected areas congruent with the needs of species from a formerly southern area; and to ensure viable, dynamic corridors where and when needed.

Spatial regimes may not follow global change trajectories when strong local drivers exist, such as immobile environmental filters (for example, sandy soil substrates and alkaline soils) or anthropogenic or geographic barriers. In these cases, theory predicts that spatial regimes will contract and not 'move through' these barriers ${ }^{36,37}$. Over time, if global drivers outweigh local drivers, spatial regime boundaries may show high variance as the local system collapses and reorganizes in the same location. For example, in our study, the southernmost spatial regime boundary (Fig. 2) corresponds broadly with the coastal prairie, which is associated with unique sandy soil types and has experienced major landscape fragmentation and conversion through urbanization and energy development ${ }^{22-27}$ (Fig. 3). The southernmost spatial regime boundary showed fidelity to the geographic boundary of the coastal prairie from 1970 to 1993 (Fig. 1). In the mid-1990s, the southernmost boundary began to vary more widely in latitude between its original location and nearly the latitude of the historic northernmost boundary (Figs. 1 and 2).

Management of spatial regimes, given their conservative nature and tools to identify their boundaries, should encourage more adaptive measures that both: (1) consider the current and potential future scale of change associated with underlying driving processes and (2) embrace ecological non-stationarity as part of short-term and longterm planning horizons. Specializations in conservation ecology

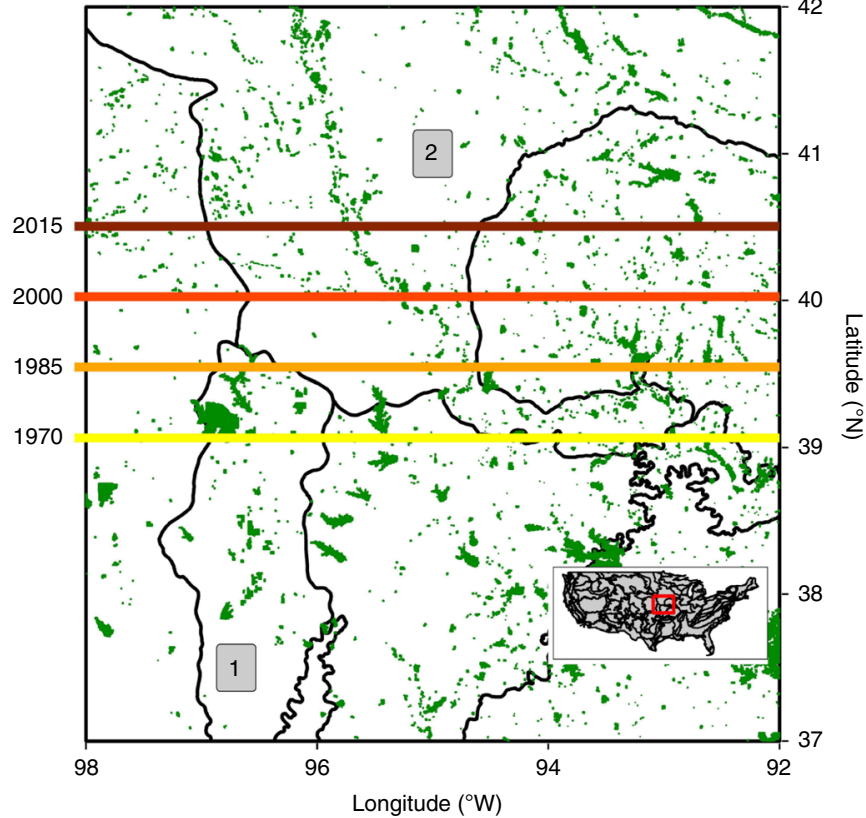

Fig. 4 | Spatial regime boundary movement between 37 and $42^{\circ}$ latitude across a network of protected areas in central North America. Black lines indicate level III US Environmental Protection Agency ecoregion boundaries; green polygons indicate protected areas. The ecoregion labelled ' 1 ' is the Flint Hills ecoregion; the ecoregion labeled ' 2 ' is the Western Corn Belt Plains ecoregion. Predicted spatial regime boundaries (coloured horizontal lines) correspond with linear predictions for the years $1970,1985,2000$ and 2015 ( $\beta=0.032 \pm 0.026^{\circ}$ latitude per year; $90 \% \mathrm{Cl}$; $F=4.093 ; P=0.052$ ).

have struggled to fully move away from the legacy of equilibrium management, despite many resilience-based management frameworks $^{34,38,39}$. We see the addition of spatial dimensionality without fixed boundaries to resilience quantification and early warning detection, particularly how spatial regimes behave over time, as a necessary ingredient for modernizing environmental management in the Anthropocene. Spatial monitoring of regime change over time could further efforts to create collaborative networks among land stewards and more strategically develop protected areas acknowledging the strong non-stationarity that currently exists $^{10,12,40}$. Instead of focusing on historic species assemblages and their idealized distribution envelopes, a successful network would focus on system-level maintenance of resilient, desirable regimes in the face of change.

\section{Online content}

Any methods, additional references, Nature Research reporting summaries, source data, statements of code and data availability and associated accession codes are available at https://doi.org/10.1038/ s41558-019-0517-6.

Received: 23 August 2018; Accepted: 22 May 2019;

Published online: 24 June 2019

\section{References}

1. Allen, C. R., Angeler, D. G., Garmestani, A. S., Gunderson, L. H. \& Holling, C. S. Panarchy: theory and application. Ecosystems 17, 578-589 (2014).

2. Dakos, V., Carpenter, S. R., Nes, E. Hvan \& Scheffer, M. Resilience indicators: prospects and limitations for early warnings of regime shifts. Philos. Trans. R. Soc. Lond. B 370, 20130263 (2015).

3. Burthe, S. J. et al. Do early warning indicators consistently predict nonlinear change in long-term ecological data? J. Appl. Ecol. 53, 666-676 (2016). 
4. Dakos, V. et al. Methods for detecting early warnings of critical transitions in time series illustrated using simulated ecological data. PloS ONE 7, e41010 (2012).

5. Carpenter, S. R. et al. Early warnings of regime shifts: A whole-ecosystem experiment. Science 332, 1079-1082 (2011).

6. Kefi, S. et al. Early warning signals of ecological transitions: Methods for spatial patterns. PloS ONE 9, e92097 (2014).

7. Cline, T. J. et al. Early warnings of regime shifts: Evaluation of spatial indicators from a whole-ecosystem experiment. Ecosphere 5, 1-13 (2014).

8. Butitta, V. L., Carpenter, S. R., Loken, L. C., Pace, M. L. \& Stanley, E. H. Spatial early warning signals in a lake manipulation. Ecosphere $\mathbf{8}$, e01941 (2017)

9. Clements, C. F. \& Ozgul, A. Indicators of transitions in biological systems. Ecol. Lett. 21, 905-919 (2018).

10. Sundstrom, S. M. et al. Detecting spatial regimes in ecosystems. Ecol. Lett. 20, 19-32 (2017).

11. Roberts, C. P. et al. Early warnings for state transitions. Rangeland Ecol. Manag. 71, 659-670 (2018).

12. Allen, C. R. et al. Quantifying spatial resilience. J. Appl. Ecol. 53, 625-635 (2016).

13. Scheffer, M., Carpenter, S., Foley, J. A., Folke, C. \& Walker, B. Catastrophic shifts in ecosystems. Nature 413, 591 (2001).

14. Strayer, D. L., Power, M. E., Fagan, W. F., Pickett, S. T. \& Belnap, J. A classification of ecological boundaries. BioScience 53, 723-729 (2003).

15. Angeler, D. G. et al. Management applications of discontinuity theory. J. Appl. Ecol. 53, 688-698 (2016).

16. Holling, C. S. Cross-scale morphology, geometry, and dynamics of ecosystems. Ecol. Monogr. 62, 447-502 (1992).

17. Spanbauer, T. L. et al. Body size distributions signal a regime shift in a lake ecosystem. Proc. R. Soc. Lond. B 283, 20160249 (2016).

18. Drake, J. M. \& Griffen, B. D. Early warning signals of extinction in deteriorating environments. Nature 467, 456 (2010).

19. Doncaster, C. P. et al. Early warning of critical transitions in biodiversity from compositional disorder. Ecology 97, 3079-3090 (2016).

20. Cohen, J. et al. Recent Arctic amplification and extreme mid-latitude weather. Nat. Geosci. 7, 627 (2014).

21. La Sorte, F. A., Hochachka, W. M., Farnsworth, A., Dhondt, A. A. \& Sheldon, D. The implications of mid-latitude climate extremes for North American migratory bird populations. Ecosphere 7, e01261 (2016).

22. Brown, D. G., Johnson, K. M., Loveland, T. R. \& Theobald, D. M. Rural land-use trends in the conterminous United States, 1950-2000. Ecol. Appl. 15, 1851-1863 (2005).

23. Chen, I.-C., Hill, J. K., Ohlemüller, R., Roy, D. B. \& Thomas, C. D. Rapid range shifts of species associated with high levels of climate warming. Science 333, 1024-1026 (2011)

24. Johnston, C. A. Agricultural expansion: land use shell game in the US Northern Plains. Landsc. Ecol. 29, 81-95 (2014).

25. Allred, B. W. et al. Ecosystem services lost to oil and gas in North America. Science 348, 401-402 (2015).

26. Donovan, V. M., Wonkka, C. L. \& Twidwell, D. Surging wildfire activity in a grassland biome. Geophys. Res. Lett. 44, 5986-5993 (2017).

27. Engle, D. M., Coppedge, B. R. \& Fuhlendorf, S. D. in Western North American Juniperus Communities (ed. Van Auken, O. W.) 253-271 (Springer, 2008).

28. Boettiger, C., Ross, N. \& Hastings, A. Early warning signals: the charted and uncharted territories. Theor. Ecol. 6, 255-264 (2013).

29. Hastings, A. \& Wysham, D. B. Regime shifts in ecological systems can occur with no warning. Ecol. Lett. 13, 464-472 (2010).

30. Clements, C. F., Drake, J. M., Griffiths, J. I. \& Ozgul, A. Factors influencing the detectability of early warning signals of population collapse. Am. Nat. 186, 50-58 (2015).
31. Scheffer, M. et al. Early-warning signals for critical transitions. Nature 461, 53 (2009).

32. Biggs, R., Carpenter, S. R. \& Brock, W. A. Turning back from the brink: detecting an impending regime shift in time to avert it. Proc. Natl Acad. Sci. USA 106, 826-831 (2009).

33. Craig, R. K. Stationarity is dead-long live transformation: five principles for climate change adaptation law. HELR Harvard Environ. Law Rev. 34, 9 (2010).

34. Twidwell, D., Allred, B. W. \& Fuhlendorf, S. D. National-scale assessment of ecological content in the world's largest land management framework. Ecosphere 4, 1-27 (2013).

35. Baho, D. L., Drakare, S., Johnson, R. K., Allen, C. R. \& Angeler, D. G. Similar resilience attributes in lakes with different management practices. PLoS ONE 9, e91881 (2014).

36. Ficetola, G. F., Mazel, F. \& Thuiller, W. Global determinants of zoogeographical boundaries. Nat. Ecol. Evol. 1, 0089 (2017).

37. Glor, R. E. \& Warren, D. Testing ecological explanations for biogeographic boundaries. Evolution 65, 673-683 (2011).

38. Briske, D., Bestelmeyer, B., Stringham, T. \& Shaver, P. Recommendations for development of resilience-based state-and-transition models. Rangeland Ecol. Manag. 61, 359-367 (2008).

39. Jantz, S. M. et al. Future habitat loss and extinctions driven by land-use change in biodiversity hotspots under four scenarios of climate-change mitigation. Conserv. Biol. 29, 1122-1131 (2015).

40. Birgé, H. E., Allen, C. R., Craig, R. K. \& Twidwell, D. in Practical Panarchy for Adaptive Water Governance (eds Consens, B. \& Gunderson, L.) 115-130 (Springer, 2018).

\section{Acknowledgements}

We thank the Complexity Working Group for conceptual development, J. L. Burnett for help in database creation, and D. Ebbeka and C. Bielski for help with data visualization. This work was supported by Department of Defense Strategic Environmental Research Development Program W912HQ-15-C-0018, Nebraska Game \& Parks Commission W-125-R-1 and the Institute of Agriculture and Natural Resources at the University of Nebraska, Lincoln. The Nebraska Cooperative Fish and Wildlife Research Unit is jointly supported by a cooperative agreement between the US Geological Survey, the Nebraska Game and Parks Commission, the University of Nebraska, the US Fish and Wildlife Service and the Wildlife Management Institute. Any use of trade, firm or product names is for descriptive purposes only and does not imply endorsement by the US Government

\section{Author contributions}

C.P.R. contributed to conceptualization, programming, validation, formal analysis, data curation, all writing aspects, visualization and project administration. C.R.A., D.G.A. and D.T. contributed to funding acquisition, conceptualization, all writing aspects and visualization.

\section{Competing interests}

The authors declare no competing interests.

\section{Additional information}

Supplementary information is available for this paper at https://doi.org/10.1038/ s41558-019-0517-6.

Reprints and permissions information is available at www.nature.com/reprints. Correspondence and requests for materials should be addressed to C.P.R.

Peer review information: Nature Climate Change thanks Eldar Rakhimberdiev and other, anonymous, reviewer(s) for their contribution to the peer review of this work.

Publisher's note: Springer Nature remains neutral with regard to jurisdictional claims in published maps and institutional affiliations.

(C) The Author(s), under exclusive licence to Springer Nature Limited 2019 


\section{Methods}

Experimental design. Breeding Bird Survey data manipulation. We used 46 years (1970-2015) of the US Geological Survey's North American Breeding Bird Survey data, which is a freely available dataset of avian community composition collected by trained observers along permanent, geo-referenced roadside routes across the North American continent ${ }^{41}$. Because routes were still being established in the initial years of the Breeding Bird Survey, especially in the Great Plains and western portions of North America, to avoid biased estimates of presence/absence we consider route data starting in 1970 , when about $50 \%$ of currently active routes had been established (Supplementary Table 1). Along each around 39.5-km route, observers make 50 stops (once every $0.8 \mathrm{~km}$ ) and conduct point-count surveys at each stop. During a point-count survey, observers stand at the stop and record the abundance of any bird species they detect visually or aurally in a $0.402-\mathrm{km}$ radius for $3 \mathrm{~min}$. Surveys begin $30 \mathrm{~min}$ before local sunrise and last until the whole route is completed. To increase uniformity in bird detection probability, observers conduct surveys only on days with low wind speeds, high visibility and little (or no) rain. Routes are distributed relatively evenly throughout the United States. Due to latitudinal differences in breeding season timing, routes may begin as early as May or as late as July.

Because of known negative observation biases for waterfowl and allied families, and because water-dwelling avian families follow different body mass patterns compared with terrestrial avian families, we removed all species from the Anseriformes, Gaviiformes, Gruiformes, Pelecaniformes, Phaethontiformes, Phoenicopteriformes, Podicipediformes, Procellariiformes and Suliformes families from the analysis ${ }^{16,41}$. We also removed hybrids and unknowns; and we condensed subspecies to their respective species.

Belt transect. Multiple global change drivers are exerting influence in a southto-north pattern in the Great Plains. For instance: climate change is shifting native and agricultural plant phenologies ${ }^{42}$ and geographic centres of plant species distributions ${ }^{43}$; woody plant encroachment is causing regime shifts from historically grassland regimes to woodland or shrubland regimes ${ }^{27,34}$; fire frequency and size has increased by $>400 \%$ in the Great Plains ${ }^{26}$; energy development such as oil and gas extraction reduced net primary productivity by about $4.5 \mathrm{Tg}$ between 2000 and 2015 (ref. ${ }^{25}$ ); agricultural land conversion has led to the northern plains losing much of its remaining grassland after commodity prices surged at the beginning of the 21 st century ${ }^{44}$; and urbanization and population growth in the Great Plains has continually increased in and around already populated $\operatorname{areas}^{22}$. To capture latitudinal spatial regime movement that may be responding to these south-to-north global change drivers, we selected a belt transect on the ecotone of the Great Plains and Eastern Temperate Forests extending from the Gulf of Mexico to the edge of the boreal forest in Canada. Specifically, the belt transect extended south-north from $28-49^{\circ}$ latitude (about 2,300 km) and east-west from $93-97^{\circ}$ longitude (about $350 \mathrm{~km}$ ).

Statistical analysis. Identifying discontinuities. For each route falling in the belt transect, we identified discontinuities in avian community body masses by rankordering the log-transformed body masses of each species observed at each route for each year. We obtained mean body mass estimates for all species in the analysis from the CRC Handbook of Avian Body Masses ${ }^{45}$. We then used the 'discontinuity detector' method ${ }^{46}$ on the log-ranked body masses, which is on the basis of the Gap Rarity Index for detecting discontinuities in continuous data ${ }^{47}$. For taxa with determinant growth, mean body mass has been shown to reliably differentiate size aggregations and is strongly allometric to the scales at which functions are carried out by organism ${ }^{48,49}$. Because the discontinuity detector method is known to overestimate discontinuities in observations with low species richness, we removed any routes with $<40$ species observed in a given year (Supplementary Table 1). We used a power table ${ }^{50}$ to account for sample size (the number of species observed at each Breeding Bird Survey route in a given year) and average variance in body masses ${ }^{45}$ to adjust the critical $d$-value (the value on the basis of Monte Carlo simulations that identifies significant discontinuities) where $N$ varied ${ }^{51}$ (Supplementary Table 2).

Spatial regime detection. To detect spatial regimes in each year, we ordered routes in ascending latitude and transformed the discontinuities into a data matrix for analysis. Specifically, in order from the lowest ranked body mass aggregation to the highest, we calculated the sizes of body mass aggregations (the log-ranked length of each aggregation), the sizes of gaps between aggregations (the log-ranked length of each gap) and the locations of aggregations (the log-transformed body mass of the species with the lowest body mass in each aggregation) for each route ${ }^{17}$. We cast these into a matrix using the 'dcast' function in the 'reshape2' and 'data. table' packages in $\mathrm{R}$, where every row represented a route in a given year and every column an aggregation size, gap size or aggregation location ${ }^{52-54}$. We calculated separate Bray-Curtis dissimilarity matrices from each year's data.

To identify spatial regimes, we ran constrained hierarchical clustering on each year's distance matrix starting at the southernmost (lowest latitude) Breeding Bird Survey route and proceeding by order of latitude to the northernmost Breeding Bird Survey route (highest latitude). Constrained hierarchical clustering directionally separates multivariate data series into homogeneous, non-overlapping segments; it constrains clusters so that only adjacent, contiguous samples (a contiguous segment of Breeding Bird Survey routes along a spatial transect) are allowed to cluster ${ }^{17,55}$. This method is commonly used to delineate temporally ordered regimes in paleo community data ${ }^{56,57}$ and to detect significant community transitions along spatial transects ${ }^{55,58}$. To perform constrained hierarchical clustering, we used the 'chclust' function with the 'CONISS' method from the 'rioja' package in $\mathrm{R}\left(\right.$ ref. ${ }^{59}$ ).

We used the broken stick model ('bstick.chclust' from the 'rioja' package in R) to determine the number of significant clusters ${ }^{17,59,60}$. The broken stick method, commonly used in conjunction with constrained hierarchical clustering, tests the distribution of clusters from constrained hierarchical clustering against multiple null random distributions of clusters to ascertain the number of significant clusters ${ }^{17,57,60}$. Because constrained hierarchical clustering identifies homogeneous, non-overlapping areas of self-similarity, significant clusters can be interpreted as regimes; boundaries between significant clusters can be interpreted as regime boundaries. Therefore, we considered the latitudes of significant cluster boundaries from each year to be the location of spatial regime boundaries from that year ${ }^{17}$.

Tracking movement in spatial regimes. We tested for non-random movement in spatial regime boundaries over time by fitting generalized additive models (' $m g \mathrm{cv}^{\prime}$ package in R) to the northernmost and southernmost spatial regime boundaries ${ }^{61}$. Because generalizing additive models did not detect non-linearity in either the northernmost (estimated degrees of freedom (edf) $=1.00, F=6.56, P=0.02$ ) or southernmost (edf $=1.00, F=3.21, P=0.08)$ spatial regime boundaries, we estimated the mean rate of movement in spatial regime boundaries using linear regression (Fig. 1). We classified the northernmost boundary each year as the spatial regime boundary with the greatest latitude; we classified the southernmost boundary each year as the spatial regime boundary with the lowest latitude. We excluded years from the linear regression analysis in which we detected no spatial regimes from the analysis $(1980,1984,1985,1990,1991,1997,1998$ and 2001). For years in which only one spatial regime boundary was detected (years with only two spatial regimes), the single boundary was counted as both the northernmost and southernmost boundary.

We also assessed spatial regime boundary movement at the scale of a regional protected areas network. Specifically, we tracked spatial regime boundary movement from 1970 to 2015 between 37 and $42^{\circ}$ latitude to assess the utility of spatial regime tracking for early warnings for land management and the length of planning horizons spatial regimes provided (Fig. 4). As above, we quantified spatial regime boundary latitudinal movement over time using linear regression.

Reporting Summary. Further information on research design is available in the Nature Research Reporting Summary linked to this article.

\section{Data availability}

All data are available in the Supplementary Data.

\section{Code availability}

$\mathrm{R}$ code and instructions for repeating analyses are available in the Supplementary Data.

\section{References}

41. Sauer, J. R. et al. The North American Breeding Bird Survey, Results and Analysis 1966-2015 (USGS Patuxent Wildlife Research Center, 2017).

42. Richardson, A. D. et al. Climate change, phenology, and phenological control of vegetation feedbacks to the climate system. Agric. For. Meteorol. 169, 156-173 (2013)

43. Hovick, T. J. et al. Informing conservation by identifying range shift patterns across breeding habitats and migration strategies. Biodivers. Conserv. 25, 345-356 (2016)

44. Drummond, M. A. et al. Land change variability and human-environment dynamics in the United States Great Plains. Land Use Policy 29. 710-723 (2012).

45. Dunning Jr, J. B. CRC Handbook of Avian Body Masses (CRC, 2007)

46. Barichievy, C. et al. A method to detect discontinuities in census data. Ecol. Evol. 8, 9614-9623 (2018).

47. Stow, C., Allen, C. R. \& Garmestani, A. S. Evaluating discontinuities in complex systems: toward quantitative measures of resilience. Ecol. Soc. 12, (2007).

48. Nash, K. L. et al. Discontinuities, cross-scale patterns, and the organization of ecosystems. Ecology 95, 654-667 (2014).

49. Sundstrom, S. M. \& Allen, C. R. Complexity versus certainty in understanding species' declines. Divers. Distrib. 20, 344-355 (2014).

50. Lipsey, M. W. Design Sensitivity: Statistical Power for Experimental Research (Sage, 1990).

51. Allen, C. R., Forys, E. A. \& Holling, C. Body mass patterns predict invasions and extinctions in transforming landscapes. Ecosystems 2, 114-121 (1999) 
52. Wickham, H. Reshaping data with the reshape package. J. Stat. Softw. 21, 1-20 (2007).

53. Dowle, M. et al. data.table: Extension of 'data.frame' v1.12.2 (CRAN, 2018); https://rdrr.io/cran/data.table/.

54. R Core Team. R: A Language and Environment for Statistical Computing (R Foundation for Statistical Computing, 2008).

55. Galzin, R. \& Legendre, P. The fish communities of a coral reef transect. Pac. Sci. 41, 1-4 (1987).

56. Vermaire, J. C., Greffard, M.-H., Saulnier-Talbot, É. \& Gregory-Eaves, I. Changes in submerged macrophyte abundance altered diatom and chironomid assemblages in a shallow lake. J. Paleolimnol. 50, 447-456 (2013).
57. Leys, B., Finsinger, W. \& Carcaillet, C. Historical range of fire frequency is not the Achilles' heel of the Corsican black pine ecosystem. J. Ecol. 102 381-395 (2014).

58. Vormisto, J., Phillips, O., Ruokolainen, K., Tuomisto, H. \& Vásquez, R. A comparison of fine-scale distribution patterns of four plant groups in an Amazonian rainforest. Ecography 23, 349-359 (2000).

59. Juggins, S. rioja: Analysis of Quaternary Science Data v0.9-21 (CRAN, 2017); https://rdrr.io/cran/rioja/man/PTF.html

60. Bennett, K. D. Determination of the number of zones in a biostratigraphical sequence. New Phytol. 132, 155-170 (1996).

61. Wood, S. Fast stable restricted maximum likelihood and marginal likelihood estimation of semiparametric generalized linear models. J. R. Stat. Soc. Lond. B. 73, 3-36 (2011) 


\section{Reporting Summary}

Nature Research wishes to improve the reproducibility of the work that we publish. This form provides structure for consistency and transparency in reporting. For further information on Nature Research policies, see Authors \& Referees and the Editorial Policy Checklist.

\section{Statistical parameters}

When statistical analyses are reported, confirm that the following items are present in the relevant location (e.g. figure legend, table legend, main text, or Methods section).

n/a Confirmed

$\square \bigotimes$ The exact sample size $(n)$ for each experimental group/condition, given as a discrete number and unit of measurement

$\square$ \ An indication of whether measurements were taken from distinct samples or whether the same sample was measured repeatedly

$\square$ The statistical test(s) used AND whether they are one- or two-sided

Only common tests should be described solely by name; describe more complex techniques in the Methods section.

$\square$ A description of all covariates tested

$\square$ \A description of any assumptions or corrections, such as tests of normality and adjustment for multiple comparisons

$\square$ A full description of the statistics including central tendency (e.g. means) or other basic estimates (e.g. regression coefficient) AND

$\triangle$ variation (e.g. standard deviation) or associated estimates of uncertainty (e.g. confidence intervals)

$\varnothing$ For null hypothesis testing, the test statistic (e.g. $F, t, r$ ) with confidence intervals, effect sizes, degrees of freedom and $P$ value noted

Give P values as exact values whenever suitable.

\ For Bayesian analysis, information on the choice of priors and Markov chain Monte Carlo settings

$\square$ For hierarchical and complex designs, identification of the appropriate level for tests and full reporting of outcomes

$\square$ Estimates of effect sizes (e.g. Cohen's $d$, Pearson's $r$ ), indicating how they were calculated

$\varnothing$ Clearly defined error bars

State explicitly what error bars represent (e.g. SD, SE, CI)

Our web collection on statistics for biologists may be useful.

\section{Software and code}

Policy information about availability of computer code

Data collection We used the publicly available North American Breeding Bird Survey dataset maintained by the US Geological Survey.

Data analysis We used R version 3.5.0 for all analyses. We have attached reproducible computer code for $\mathrm{R}$ statistical software, and we have reported sources for functions and code not available via CRAN packages.

For manuscripts utilizing custom algorithms or software that are central to the research but not yet described in published literature, software must be made available to editors/reviewers upon request. We strongly encourage code deposition in a community repository (e.g. GitHub). See the Nature Research guidelines for submitting code \& software for further information.

\section{Data}

Policy information about availability of data

All manuscripts must include a data availability statement. This statement should provide the following information, where applicable:

- Accession codes, unique identifiers, or web links for publicly available datasets

- A list of figures that have associated raw data

- A description of any restrictions on data availability

All data is freely available via the U.S. Geological Survey's North American Breeding Bird Survey database. We have also included the body mass and species presence/absence data used in a supplementary file along with reproducible computer code. 


\section{Field-specific reporting}

Please select the best fit for your research. If you are not sure, read the appropriate sections before making your selection.

Life sciences

Behavioural \& social sciences

Ecological, evolutionary \& environmental sciences

For a reference copy of the document with all sections, see nature.com/authors/policies/ReportingSummary-flat.pdf

\section{Ecological, evolutionary \& environmental sciences study design}

All studies must disclose on these points even when the disclosure is negative.

Study description

Research sample

Data collection

Timing and spatial scale

Data exclusions

Reproducibility

Blinding
Sampling strategy

Randomization

We used North American Breeding Bird Survey data (BBS) along a south-to-north belt transect extending south-north from $28-49$ degrees latitude (approximately $2300 \mathrm{~km}$ ) and east-west from $93-97$ degrees longitude (approximately $350 \mathrm{~km}$ ). We then identified spatial boundaries in bird regimes (spatial regimes) and tracked their movement over time.

We collected 46 years (1970 - 2015) of the U.S. Geological Survey's North American Breeding Bird Survey data (BBS), which is a freely available dataset of avian community composition collected by trained observers along permanent, georeferenced roadside routes across the North American continent. Because routes were still being established in the initial years of the BBS, especially in the Great Plains and western portions of North America, to avoid biased estimates of presence/absence we consider route data starting in 1970, when approximately 50\% of currently active routes had been established (Table S1). Along each approximately $39.5 \mathrm{~km}$ route, observers make 50 stops (once every $0.8 \mathrm{~km}$ ) and conduct point-count surveys at each stop. During a point-count survey, observers stand at the stop and record the abundance of any bird species they detect visually or aurally within a $0.402 \mathrm{~km}$ radius for three minutes. Surveys begin thirty minutes prior to local sunrise and last until the whole route is completed. To increase uniformity in bird detection probability, observers conduct surveys only on days with low wind speeds, high visibility, and little or no rain. Routes are distributed relatively evenly throughout the United States. Due to latitudinal differences in breeding season timing, routes may begin as early as May or as late as July.

Our sample size was simply the number of North American Breeding Bird Survey routes conducted each year within our study area. We established the belt transect due to the multiple global change drivers (e.g., climate change) influencing ecological regimes along the ecotone of the Great Plains and Eastern Temperate Forests extending from the Gulf of Mexico to the edge of the boreal forest in Canada.

The North American Breeding Bird Survey conducts annual roadside avian point-count surveys. These surveys are conducted by volunteers and compiled in a central database maintained by the US Geological Survey.

We analyzed data from the North American Breeding Bird Survey from 1970 - 2015. Data is collected annually. We considered all breeding bird data extending south-north from 28-49 degrees latitude (approximately $2300 \mathrm{~km}$ ) and east-west from $93-97$ degrees longitude (approximately $350 \mathrm{~km}$ ).

Because the discontinuity analysis method we used became biased at low species richness, we excluded breeding bird survey routes on which $<30$ bird species were detected. This is an established cutoff in the literature--see our citations for reference.

Additionally, because of known negative observation biases for waterfowl and allied families and because water-dwelling avian families follow different body mass patterns than terrestrial avian families, we removed all species from the Anseriformes, Gaviiformes, Gruiformes, Pelecaniformes, Phaethontiformes, Phoenicopteriformes, Podicipediformes, Procellariiformes, and Suliformes families from the analysis. We also removed hybrids and unknowns, and we condensed subspecies to their respective species.

Because the number of survey routes varied across years, we initially checked our results by only using survey routes that were established in the beginning of the study (1970) and were repeated every year after. Although this resulted in a lower sample size, we found results (spatial regime movement patterns) were extremely similar to when we used the entire dataset.

Because our analysis determined the groups we analyzed (i.e., spatial regime boundaries), randomization was not required.

Because our data was collected from a publicly-available database, we did not use blinding.

Did the study involve field work? $\square$ Yes $\square$ No 
Materials \& experimental systems

$\mathrm{n} / \mathrm{a}$ Involved in the study

\ $\square$ Unique biological materials

Х $\square$ Antibodies

\ $\square$ Eukaryotic cell lines

Х $\square$ Palaeontology

$\triangle \square$ Animals and other organisms

$\bigotimes \mid \square$ Human research participants
Methods

$\mathrm{n} / \mathrm{a}$ Involved in the study

$\triangle(\square$ ChIP-seq

Х $\square$ Flow cytometry

$\searrow \mid \square$ MRI-based neuroimaging 


\section{Title: Shifting spatial regimes in a changing climate}

\section{Supplementary Tables}

Supplementary Table 1. For each year of analysis, number of North American Breeding Bird Survey routes falling within the belt transect, number of routes used in analysis (where $\geq 40$ bird species were recorded in a given year), and number of routes removed from analysis (where $<40$ bird species were recorded in a given year).

\begin{tabular}{|c|c|c|c|}
\hline Year & N Routes in Transect & Used & Removed \\
\hline 1970 & 124 & 112 & 12 \\
\hline 1971 & 122 & 122 & 0 \\
\hline 1972 & 110 & 97 & 13 \\
\hline 1973 & 128 & 120 & 8 \\
\hline 1974 & 123 & 116 & 7 \\
\hline 1975 & 128 & 121 & 7 \\
\hline 1976 & 126 & 115 & 11 \\
\hline 1977 & 133 & 122 & 11 \\
\hline 1978 & 146 & 146 & 0 \\
\hline 1979 & 148 & 148 & 0 \\
\hline 1980 & 145 & 139 & 6 \\
\hline 1981 & 139 & 139 & 0 \\
\hline 1982 & 133 & 133 & 0 \\
\hline 1983 & 134 & 134 & 0 \\
\hline 1984 & 142 & 132 & 10 \\
\hline 1985 & 135 & 135 & 0 \\
\hline 1986 & 142 & 142 & 0 \\
\hline 1987 & 146 & 146 & 0 \\
\hline 1988 & 141 & 135 & 6 \\
\hline 1989 & 135 & 131 & 4 \\
\hline 1990 & 136 & 130 & 6 \\
\hline 1991 & 143 & 135 & 8 \\
\hline 1992 & 160 & 157 & 3 \\
\hline 1993 & 165 & 159 & 6 \\
\hline 1994 & 172 & 166 & 6 \\
\hline 1995 & 191 & 183 & 8 \\
\hline 1996 & 175 & 167 & 8 \\
\hline 1997 & 174 & 150 & 24 \\
\hline 1998 & 172 & 166 & 6 \\
\hline 1999 & 176 & 164 & 12 \\
\hline 2000 & 180 & 174 & 6 \\
\hline 2001 & 178 & 169 & 9 \\
\hline 2002 & 168 & 158 & 10 \\
\hline 2003 & 202 & 191 & 11 \\
\hline
\end{tabular}




\begin{tabular}{rrrr}
2004 & 211 & 199 & 12 \\
2005 & 207 & 193 & 14 \\
2006 & 200 & 188 & 12 \\
2007 & 204 & 204 & 0 \\
2008 & 200 & 186 & 14 \\
2009 & 205 & 197 & 8 \\
2010 & 207 & 197 & 10 \\
2011 & 209 & 199 & 10 \\
2012 & 215 & 202 & 13 \\
2013 & 210 & 210 & 0 \\
2014 & 213 & 213 & 0 \\
2015 & 195 & 195 & 0 \\
\hline
\end{tabular}

Supplementary Table 2. Power table for use with the "discontinuity detector" method from Barichievy et al. (2018). Columns indicate the species richness at which "d-values" produced by the discontinuity detector indicate a significant gap between log-ranked body masses.

\begin{tabular}{rr} 
Richness & d-value \\
\hline 40 & 0.48 \\
50 & 0.53 \\
60 & 0.58 \\
70 & 0.65 \\
80 & 0.71 \\
90 & 0.75 \\
100 & 0.78 \\
110 & 0.8
\end{tabular}

